\title{
BDA accredits Cyprus dental centre
}

A dental service for British armed forces in Cyprus has received a BDA Good Practice Scheme accreditation.

Dental Centre Episkopi has achieved a double first because it is the first military and first overseas practice to join the scheme.

The centre is one of four Defence Dental Services (DDS) practices in Cyprus that provide care for the British military community. Episkopi has a population of 2,500 including 1,000 service personnel, their families and supporting organisations. The centre is the headquarters of the British Sovereign Base Area on the island so civil servants are also entitled to receive treatment.

Dental Officer Major Eamonn Murphy and Practice Manager Sergeant Steve Mear, both in the Royal Army Dental Corps, attended the previous BDTA Dental Showcase where a GPS plaque was presented by the BDA president.

According to the team, military dentistry

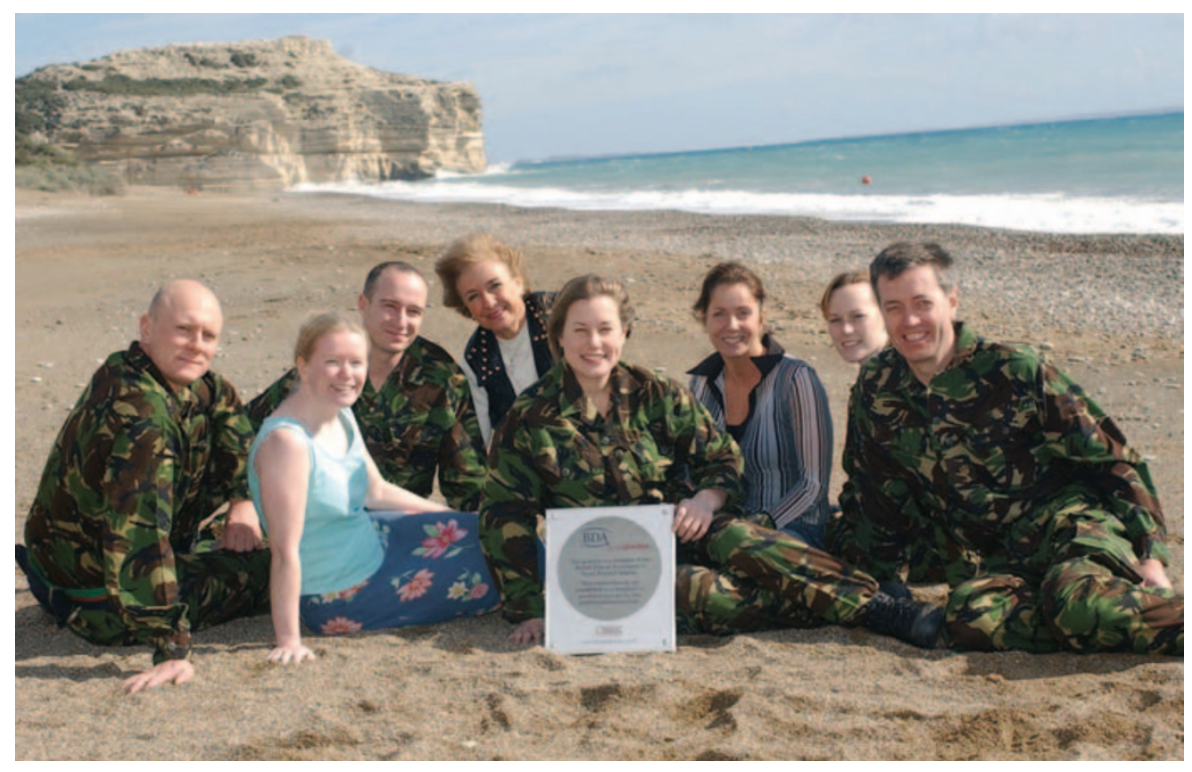

has a different emphasis to general civilian practice. The DDS's priority is to maintain the health of the soldiers to minimise the risk of problems during military campaigns. Ultimately DDS aims to provide the best possible treatment for patients.

\section{Surgeries unite for oral health}

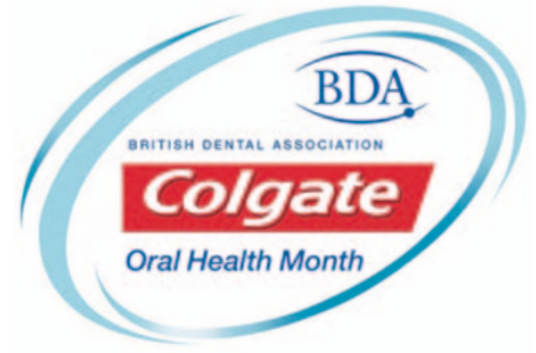

Dental surgeries nationwide have been participating in Colgate's oral health month campaign, which aims to promote good oral health habits among the general public.

The theme of this year's programme is "fighting together for better oral health". The key messages are brushing teeth twice a day with a fluoride toothpaste, changing toothbrushes every three months, visiting the dentist regularly and avoiding sugary foods between meals.

Colgate, in partnership with dental professionals, has been delivering this patient information by providing educational materials and appropriate samples.

\section{Lecture tour}

\section{celebrates 20th year}

The GlaxoSmithKline Consumer Healthcare (GSK) Talking Points in Dentistry programme celebrates its 20th anniversary this year.

The event, which toured the country for three weeks earlier this year, has presented more than 5,000 dental professionals with lectures on cutting edge clinical and policy issues in dentistry.

This year the tour visited 12 venues including the BDA Conference and Exhibition in Glasgow.

At this meeting Stephen Hancocks, Editorin-Chief of the British Dental Journal, discussed how the dental team could save lives by helping patients to quit smoking and covered the health consequences of tobacco use.

Chris Barrow from the Business Coaching Company spoke about building a championship support team. He described a nine-point plan for team building that he called key in separating winners from losers.

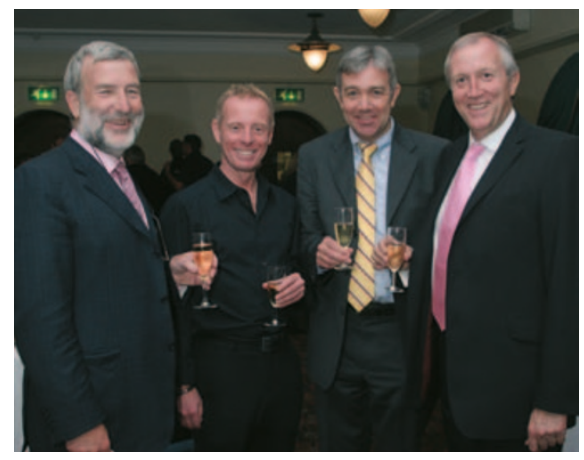

Roy Higson, Chris Barrow, Stephen Hancocks and Trevor Burke

His plan covered areas such as behavioural problems, organisational structure and business functions, motivation, vision, and delegation.

Talking Points, first introduced by GSK in 1985 , is designed to provide a new and innovative type of educational seminar covering a wide range of relevant topics and issues suitable for the entire dental team. 